\title{
Global activity distribution patterns of top international Chinese contractors
}

\author{
Chuan Chen ${ }^{1,}$ a , Hongjiang $\mathrm{Li}^{1, \mathrm{~b}}$ and Igor Martek ${ }^{2, \mathrm{c}}$ \\ ${ }^{1}$ School of Business, Sichuan University, Chengdu 610064, China \\ ${ }^{2}$ School of Architecture and Built Environment, Deakin University, Geelong 3220, Australia \\ achenchuan@scu.edu.cn, blihongjiang2012@foxmail.com, cigor@deakin.edu.au
}

\begin{abstract}
Top international Chinese contractors' (TICCs) are now major influential players in the global construction market. The last two decades have witnessed a remarkable growth in their global rankings, by revenue. The spatial distribution and expansive behaviors of TICCs are of interest to international contractors generally, as well as to national infrastructure procurers. Nevertheless, few researchers have considered the spatial distribution of TICCs. This study demonstrates that TICCs' market selection and market positioning are not independent, but have similar characteristics. Clustering methods were used to order the data, with ESDA methods used to analyze the data. The key findings are that TICCs' target specific national markets and that these markets tend to be geographically proximate creating regional agglomerations. The inference to be drawn is that TICCs tend to follow in each other's footsteps as they expand globally.
\end{abstract}

Keywords: Global distribution; spatial patterns; Chinese contractors; international construction; ESDA; national agglomerations; regional agglomerations; spatial autocorrelation.

\section{Introduction}

Chinese international construction companies have made dramatic gains in the global construction market in recent years. According to Engineering News Record (ENR) (2013), there are 55 Chinese companies on ENR's list of the 'Top 250 International Contractors.' These 'top international Chinese contractors' (TICCs) realized a total contracting revenue of US\$67.07 billion from their overseas market operations in 2012. Despite the rising importance of TICCs on the world construction scene, the spatial distribution of TICCs has not yet been the subject of focused research. Where the topic is raised in business studies, the matter is generally treated incidentally. Typically, the participation of firms in global markets is analyzed through the proxy of revenues generated, which is problematic given the wild fluctuations and variation in earnings year-to-year and place-to-place. Moreover, the geographical units of study tend to be undertaken at the continent level, ignoring national differences, while the methods of study tend to be qualitative rather than quantitative. Such broad approaches facilitate broad generalizations rather than precise profiling. Nevertheless, of the studies in the field carried out so far, two are noteworthy. The first is by Pheng, Jiang and Leong (2004); the other by Chen and Orr (2009).

Sui, Pheng and Hongbin (2003) discussed the internationalization of Chinese construction enterprises and found that their traditional markets are in the developing countries of Africa and the Middle East, such as Pakistan and Iraq. In subsequent work, Pheng documented the dynamic expansion of internationalizing construction firms, arguing that globalization was a sequenced process, beginning with expansion into Asia, then to Africa, North America and East Europe, and only finally to Latin America (Pheng, Jiang and Leong, 2004). Chen and Orr (2009) investigated Chinese construction firms in Africa, finding that even though Africa is a traditional overseas market for Chinese contractors, their geographic distribution across countries varies sharply.

However, these previous studies do not generate a clear picture of the global distribution status of Chinese contractors. Firstly, they concentrate on specific regions of the world, especially those characterized by the presence of many Chinese contractors, such as Africa and Asia, while neglecting other parts of the world. Secondly, they also ignore the spatial correlations of the distribution of international Chinese contractors; considering countries only in isolation. These deficiencies are resolved in this research study. 


\section{Data collection and methodology}

In order to analyze the spatial pattern of TICCs, international business spatial distribution data was collected for each of the TICCs identified by ENR. ENR is widely regarded as the most reliable provider of international construction data. These data were then analyzed using standard methods, including Jenks natural breaks classifications, and exploratory spatial data analysis (ESDA).

Jenks' classification method is a well-known technique for generating natural breaks in data sets, and this was used. The method seeks to reduce the variance within classes, while maximizing the variance between classes.

ESDA is data-driven, with the main function being to identify non-random spatial distributions and spatial autocorrelations. Two kinds of tools are used in ESDA: 'global spatial autocorrelation,' and 'local spatial autocorrelation.' Global spatial autocorrelation measures the degree of association between spatial units, making it possible to judge whether there are any significant spatial patterns between spatial units. 'Moran's I,' is one of the more familiar measures of global spatial autocorrelation (Rey 2001). Moran's I index is usually interpreted as a correlation coefficient, ranging from -1 to +1 . An ' $I$ ' index figure greater than 0 indicates a positive correlation; a value close to 1 indicates that units with similar attributes gather together. An ' $\mathrm{I}$ ' index figure less than 0 indicates a negative correlation; a value close to -1 indicates that units with diverse attributes gather together. An ' $\mathrm{I}$ ' index figure close to zero indicates random distribution of the variable, with no significant spatial autocorrelation.

Anselin (1995) has suggested a class of local indicators of spatial association (LISA) for the analysis of spatial clustering in hot spots. 'Local Moran's I' is one of the most widely used local spatial autocorrelation indices. A positive local Moran index Ii indicates that where country i has a high attribute value, it is also surrounded by countries with high attribute values (high - high), or, where country i has a low attribute value, it is similarly surrounded by countries with low attribute values (low - low). However, a negative Moran index Ii indicates that where country i has a high attribute value, it is surrounded by countries with low attribute values (high - low), or, where country i has a low attribute value, it is surrounded by countries with high attribute values (low - high). Thus the local Moran's index can be used to identify and quantify spatial concentrations.

\section{Data analysis}

\subsection{Concentration of TICCs into specific countries}
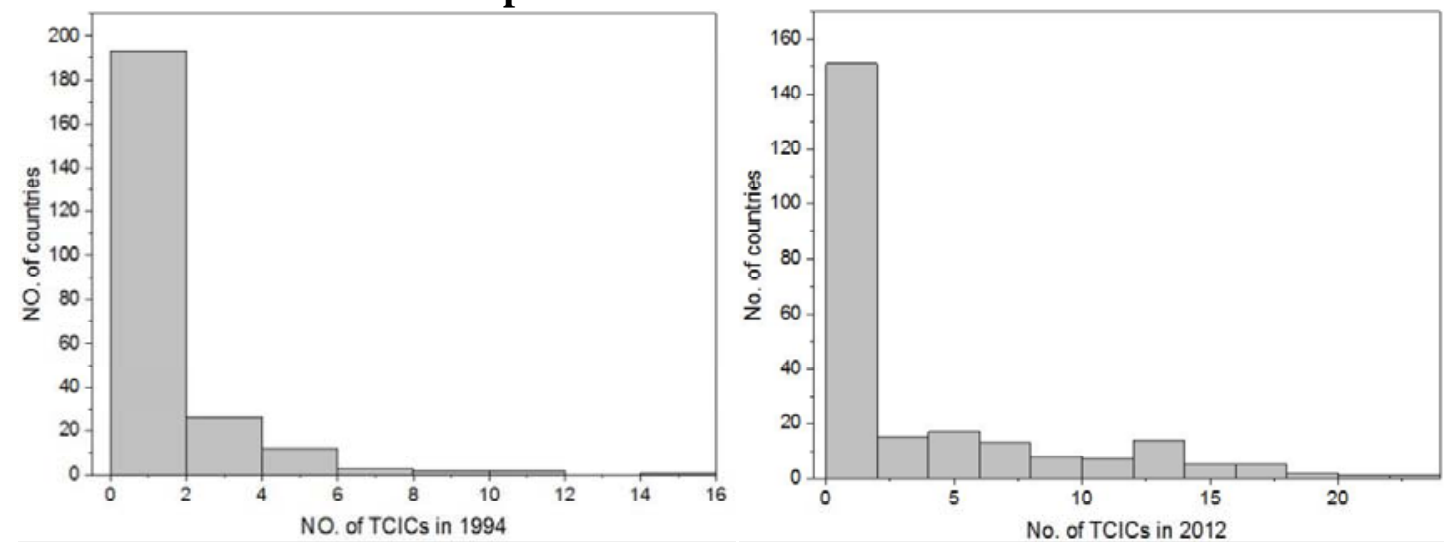

Fig 1. Histogram of the number of TICCs in different countries (1994 and 2012)

The country distribution of TICCs is neither equally spread, nor random. On the contrary, TICCs are found to concentrate heavily into a limited number of specific countries. Most countries receive no construction activity from TICCs, whatsoever. This tendency to national agglomeration of TICCs is shown in Figure 1. This figure contrasts the country distribution of TICCs both at the beginning and at the end of the study period; 1994 and 2012. In 1994, of the world's nearly 200 countries, one country had 14 TICCs simultaneously undertaking projects within it. Another country had 10, another 8 , and another 6 . A few more had 2 or more TICCs, with the remaining countries world-wide hosting 
one or none. Similarly, in 2012, a rare few number of countries were host to large numbers of TICCs, some had a few TICCs, and the rest of the world had no TICC representation.

The question which follows is, which are the countries attracting the highest concentration of TICCs, and which countries attract none. To do this, Jenks' classification method was used. Countries were allocated into one of four clusters: intensive, normal, few, and rare. Arcgis software was used to graph the results, which are shown as Figure 2.

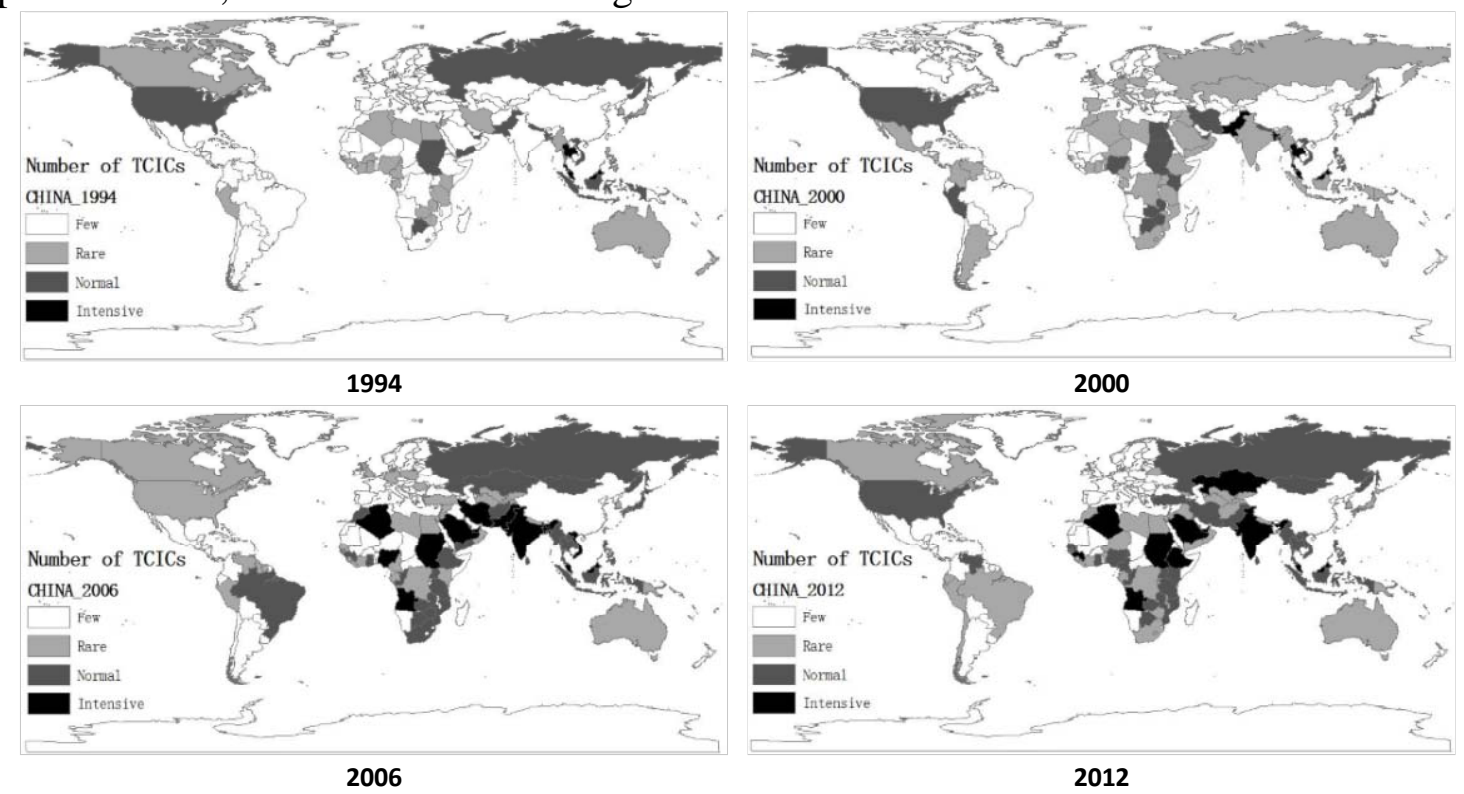

Fig 2. Jenks natural breaks classification results (1994, 2000, 2006 and 2012)

The findings reveal that over the whole duration of the study period, the international construction business of TICCs remains concentrated in Asia, the Middle East, and Africa, and to a lesser extent, the United States. On the other hand, TICCs show almost no continuous presence in Europe or Latin America, with limited representation in Australia. From a longitudinal perspective, a dynamic shift can be observed. TICCs moving off-shore from China initially focus on South-east Asian countries, then expand to Middle Eastern countries, and then to African countries, all the while retaining their presence in South-east Asia. Conversely, throughout the entire 19 years of the study period, TICCs are hardly represented in the rest of the world.

At the national scale, TICCs, too, follow a regimented and predictable expansion from country to country. TICCS typically begin with off-shore projects in the South-east Asian countries of Malaysia, Singapore and Thailand. With the passing of time, these TICCs, expand westward to West Asian countries such as Bangladesh, India, Pakistan and Kazakhstan, then to Middle Eastern countries such as Iran and Saudi Arabia, and finally to African countries such as Ethiopia, Sudan, Algeria, Angola and Guinea.

Simply, the spatial clustering of TICCs occurs as national agglomerations in a few, limited countries.

\subsection{Concentration of TICCs into specific regions}

The above results show that the distribution of TICCs exhibit both national agglomerations, as well as regional agglomerations. That is, a country with many TICCs can expect to be surrounded by other countries also with many TICCs, Similarly, a country with only a limited number of TICCs, can expect that its neighboring countries will also have few TICCs, if any. Thus, the number of TICCs across various countries is not spatially random, but rather, is spatially auto-correlated. In order to confirm the existence of auto-correlation a yearly global Moran's I index was calculated for the data. The results are summarized in Table 1.

The results show that all p-values (whether as $\mathrm{p}-(\mathrm{N})$ or $\mathrm{p}-(\mathrm{P})$ ), are less than 0.01 . This indicates that Moran's I is significant every year, which means that the distribution of TICCs is not spatially random. Moreover, since all Moran's I are positive, it is clear that distribution of TICCs is positively 
spatially auto-correlated. That is, those countries with many TICCs operating within them tend to be regionally proximate, if not adjacent to each other.

Table 1. Global Moran's I and its tests

\begin{tabular}{|c|c|c|c|c|c|c|c|c|c|}
\hline Year & Moran I & $\mathrm{z}$ & $\mathrm{p}-(\mathrm{N})$ & $\mathrm{p}-(\mathrm{P})$ & Year & Moran I & $\mathrm{z}$ & $\mathrm{p}-(\mathrm{N})$ & $\mathbf{p}-(\mathbf{P})$ \\
\hline 1994 & 0.22 & 3.68 & 0.00 & 0.00 & 2004 & 0.38 & 6.35 & 0.00 & 0.00 \\
\hline 1995 & 0.23 & 3.86 & 0.00 & 0.00 & 2005 & 0.42 & 6.93 & 0.00 & 0.00 \\
\hline 1996 & 0.29 & 4.83 & 0.00 & 0.00 & 2006 & 0.39 & 6.43 & 0.00 & 0.00 \\
\hline 1997 & 0.23 & 3.81 & 0.00 & 0.00 & 2007 & 0.35 & 5.83 & 0.00 & 0.00 \\
\hline 1998 & 0.31 & 5.20 & 0.00 & 0.00 & 2008 & 0.33 & 5.45 & 0.00 & 0.00 \\
\hline 1999 & 0.34 & 5.64 & 0.00 & 0.00 & 2009 & 0.35 & 5.82 & 0.00 & 0.00 \\
\hline 2000 & 0.33 & 5.45 & 0.00 & 0.00 & 2010 & 0.34 & 5.64 & 0.00 & 0.00 \\
\hline 2001 & 0.41 & 6.71 & 0.00 & 0.00 & 2011 & 0.36 & 6.03 & 0.00 & 0.00 \\
\hline 2002 & 0.43 & 7.09 & 0.00 & 0.00 & 2012 & 0.37 & 6.16 & 0.00 & 0.00 \\
\hline 2003 & 0.38 & 6.24 & 0.00 & 0.00 & & & & & \\
\hline
\end{tabular}

Notes: $\mathrm{p}-(\mathrm{N})$ is result assuming distribution of the number of TCICs is normal distribution.

$\mathrm{p}-(\mathrm{P})$ is result assuming distribution of the number of TCICs is random distribution.

Two chronological trends are apparent, with the year 2000 being the pivotal year around which a change is evident. Prior to 2000, Moran's I grows year on year, indicating that spatial auto-correlation is growing. As TICCs move out of China to undertake business off-shore, they tend to move into the same countries, and enter the same markets, in which other TICCs are already operating. Post 2000, Moran's I levels off and remains stable. This indicates a consolidation of the established spatial pattern achieved by TICCs; the numbers of TICCs operating in countries, too, also leveling off.

In discerning specific regional agglomerations of TICCs, the LISA clustering analysis technique was used, utilizing QUEEN's spatial weighted matrix. The results are shown in Figure 3.
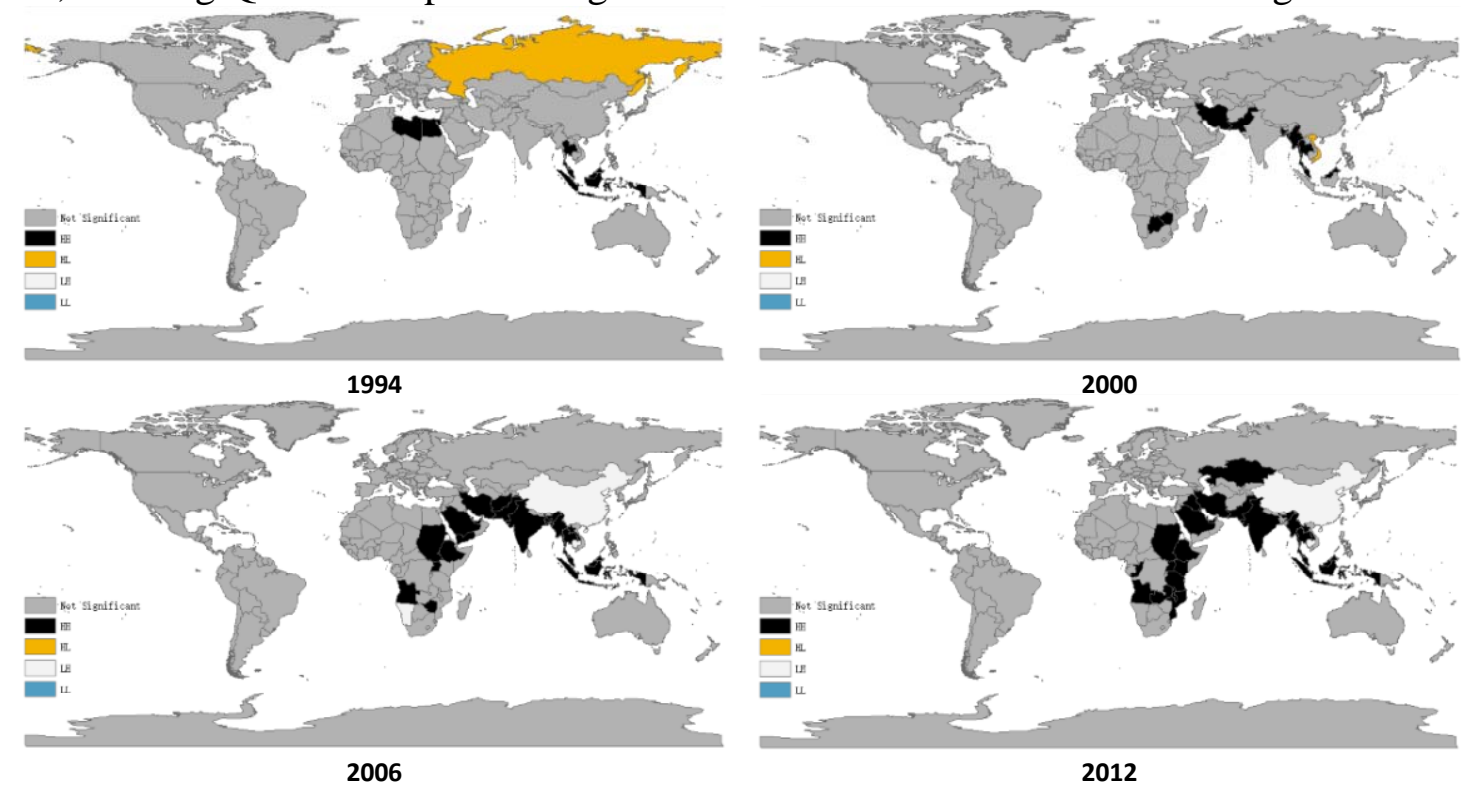

Fig 3. LISA cluster of TCICs (1994, 2000, 2006 and 2012)

The LISA clustering results reveal that for most countries there are no significant regional agglomerations for TICCs, with the number of TICCs in these countries being spatially random. Whether the number of TICCs in these countries is large or small, neighboring countries cannot be said to have either similar or dissimilar numbers of TICCs. Simply, these countries show no regional agglomerations.

However, there are some particular countries and regions exhibiting 'high-high' clusters. This means that the neighboring countries of a country with many TICCs, will also have similarly high numbers of TICCs. This tendency forms a regional agglomeration of TICCs. Such TICC agglomerations can be found in Asia, the Middle East and Africa. Prior to the year 2000, there were 
few regional agglomerations, and these were typically in South-east Asia. After 2000, agglomerations began to develop westward, appearing in the Middle East and Africa.

\section{Summary}

The global spatial distribution pattern of TICCs is far from random. TICCs show strong tendencies to cluster spatially, and do so with three clear characteristics.

Firstly, TICCs show a tendency to national agglomeration. That is, TICCs gravitate to a limited number of specific countries, and neglect the majority of remaining countries. Secondly, TICCs also show a tendency to regional agglomeration. That is, countries which attract TICCs are themselves geographically proximate to those other countries which attract TICCs. These geographically linked countries form precincts, or regions, and are located in Asia, the Middle East and Africa. Finally, the spatial distribution of TICCs is relatively stable over time. That is, while the number of TICCs active globally may change, increasing as it has over the last couple of decades, the distribution of those TICCs remains concentrated in the same few countries and regions.

These findings confirm widely held anecdotal evidence that Chinese construction contractors do indeed favor specific markets and regions in expanding their global operations. The limitation of this study is that it does not examine why TICCs have made the choices they have. There are no shortage of theories. It may be that China has expanded geographically, ranging increasingly further afield over time simply as opportunities arise. It may be that China, as a relative late-comer, has moved into markets not yet taken up, or held to be less attractive by more established global constructors. It may be that China has targeted countries on political motivations; dealing with governments that have less cordial ties with the west, or as a result of government to government developmental aid, financing, or trade agreement arrangements. The factors which motivate TICC market choices will be of interest to academics and practitioners alike, and with this study, such an inquiry becomes ripe for exploration.

\section{References}

[1]. Pheng L.S, Jiang H, and Leong C. H. A comparative study of top British and Chinese international contractors in the global market. Construction Management \& Economics, Vol. 22 (2004) No. 7, p. 717-731.

[2]. Chen C, and Orr R. J. Chinese contractors in Africa: Home government support, coordination mechanisms, and market entry strategies. Journal of Construction Engineering and Management, Vol. 135 (2009) No. 11, p. 1201-1210.

[3]. Sui Pheng L., and Hongbin J. Internationalization of Chinese construction enterprises. Journal of construction engineering and management, Vol. 129 (2003) No. 6, p. 589-598.

[4]. Rey, S. J. (2001). Spatial empirics for economic growth and convergence. Geographical Analysis, Vol. 33 (2001) No. 3, p. 195-214.

[5]. Anselin, L. (1995). Local indicators of spatial association-LISA. Geographical analysis, Vol. 27 (1995) No. 2, p. 93-115. 